\title{
Tourism Economy and Tourism Ecological Environment
}

\author{
Tingting Shi \\ Xi’an International University, Shaanxi Xi’an, 710077, China
}

Keywords: tourism economy; tourism ecology; ecological environment;

\begin{abstract}
The tourism industry has become an important part of China's economic growth. With the gradual development of tourism, tourism economy has become an important part of national income. At the same time, the destruction of tourism ecological environment is becoming more and more serious. The development of tourism largely depends on local natural scenery and species, but the development has also caused serious damage to it. It is necessary to ensure the sound development of tourism and maintain the local tourism ecological environment. This paper discusses the correlation of tourism economy and ecological environment in detail, and provides some suggestions for maintaining the balance between tourism economy and tourism ecological environment.
\end{abstract}

\section{Introduction}

Tourism is a very comprehensive industry, which is rooted in the local environment and resources, and as an effective upgrade to the local economy, the formation of tourism economy. However, with the rapid development of tourism economy, the local tourism ecological environment has been changed or destroyed to some extent. People's pursuit of tourism economy, while promoting local economic growth, but also broke the balance of local tourism economy and tourism ecological environment. So, will inevitably cause irreparable damage to the local tourism industry, and even make the foundation of the entire tourism economic development destroyed.

\section{The Economic Function of Tourism}

The development of tourism has a positive effect on local economy.

First, tourism increased the relevance of the local industry, such as accommodation, transportation, catering, etc.

Secondly, increase the local employment rate. Tourism is a comprehensive service industry, every link needs professional tourism reception staff, such as hotel attendants, restaurant attendants, scenic management personnel, etc. Each tourist resort has its own specialty. Before the formation of tourism, these specialty sales area and visibility are very limited, and did not form a good sales model. In production and processing, but also by small business units or a single family production, can not form a certain scale and brand. But with the local tourism reception has been strengthened, the number of tourists increased, the demand for souvenirs / specialty will continue to improve. So, will certainly stimulate local residents have joined the ranks of related products, rather than confined to small-scale manufacturing [1]. Since the foundation of tourism is the local tourism resources (such as natural landscape or cultural landscape), in order to make better development of tourism, the local management is bound to spend enough manpower and material resources to maintain the local tourism resources, to ensure that the tourism economy will have a benign growth. Encourage people to learn local culture, which for some of the local intangible cultural heritage has some protection.

As the positive impact of tourism economy on the local economy is very obvious, resulting in a lot of tourism places are too attached importance to the development of tourism economy. But the tourism industry is a very comprehensive service industry, the need for a comprehensive tourism, planning, effective co-ordination management, otherwise it is bound to cause immeasurable negative impact [2]. Because tourism economy is seasonal, tourism areas generally have unbalanced 
economic development. For example, in the season, often there will be serious traffic jams in the local hotel, hard to find a room. In the off-season, there will be a lot of tourism equipment is idle, the hotel will be a deserted house. ". This seasonal industry season will also cause the relevant service personnel "seasonal unemployment". And this blowout economic growth mode, it is bound to affect the stable development of the local [3].

\section{The Impact of Tourism on Ecological Environment}

Tourism ecological environment is the fundamental of tourism development. When a local need to develop tourism, is bound to make improvements to the area of the whole tourism background, creating a "green mountains and rivers, rich historical and cultural heritage birds'twitter and fragrance of flowers," the tourism environment. Local government and relevant departments will actively invest in fitness work and protection work. For example, China's "green city" on the assessment of a strong local environment to promote the planning and construction, which ranks the forefront of Guilin has become a well-known tourist city.

Economic growth and environmental sustainability are incompatible [4]. The development of tourism lies in the development of tourism. In order to better enhance the local tourism reception capacity, many scenic spots in the original natural lot wantonly road construction, construction of hotels or sightseeing facilities (such as cable cars). This will inevitably cause local soil erosion, serious environmental pollution and landscape changes, etc.. Because our country's current tourism resources development technology is still in the extensive, resulting in most tourism resources can not be reasonable use, further aggravate the destruction of tourism ecological environment.

At the same time, with the increase in the number of tourists, a large number of vehicles and tourists into the scenic spots, will inevitably affect the normal habitat of animals in the scenic spots. Some tourists in the scenic area of low quality, love freely in urinating, graffiti, climbing, have caused serious damage to the environment and the cultural heritage scenic spots. At present, most tourists are two and above tourism, so will inevitably produce a lot of domestic garbage and food waste, affect the environmental health tourism.

\section{Contradiction between Tourism Economy and Tourism Ecological Environment}

In the traditional view of tourism development, tourism economy has the characteristics of small investment, quick effect and renewable tourism resources. Therefore, we should seize every opportunity to develop tourism and maximize the development of tourism economy. Vigorously promote the tourism economy to promote local development, this understandable. However, if only emphasize the benefits of tourism to local economic growth, it is easy for people to ignore the protection of tourism ecological environment. The cause for the construction of environmental protection funds to be used for construction of tourism facilities, ignoring the natural environment to recuperate the time required conditions and space conditions. Thus causing the destruction of tourism ecological environment, and even threaten the living environment of mankind.

Tourism ecological environment is the basis and fundamental of tourism economic development, once the tourism ecological environment destroyed, resulting in some species or scenery disappear, as a selling point of the development of tourism economy will collapse. However, due to the change of tourism ecological environment with time, after a period of time will be reflected. Tourism developers and operators attach too much importance to the growth of tourism economy and ignore the change of tourism ecological environment. Eventually formed a vicious circle, leading to the decline of local tourism economy. International tourism research found that climate change in 2050 will lead to a decline in the number of tourists in the Mediterranean region 11100 19800 million, local tourism revenue will decline 64 billion 1100 billion [5].

\section{Measures Balancing Tourism Economy and Tourism Ecological Environment}

Environmental tax (Environmental Taxation), also known as ecological tax, green tax, is the late 
twentieth Century international tax academic circles rise concept. So far, environmental taxes do not have a standard, broad, uniform definition. But scholars generally believe that environmental tax refers to caused by environmental pollution and ecological damage and pollution social costs into production costs and market prices, and the use of market mechanisms to improve the environment of a resource distribution mode of economic rationality of [6]. At present, some developed countries in Europe began to levy sulfur dioxide tax, water pollution tax, noise tax, solid waste tax and garbage tax and other 5 kinds of environmental taxes. December 2011, China's Ministry of Finance agreed to timely introduction of environmental taxes; in December 2, 2013, the environmental tax program has been submitted to the State Council and is under the program review [7]. But most of our tourism enterprises do not recognize the positive role of environmental tax on tourism economy and tourism ecological environment. On the other hand, it also reflects China's tourism enterprises for environmental protection is not enough to form a protective consciousness, not understanding that if we do not own before tourism caused by the destruction of ecological environment, "pay" will lead to the collapse of the tourism economy, and even the destruction of the human living environment. Therefore, China's tourism management departments, tax departments and financial departments should vigorously promote the significance and role of environmental taxes, and gradually enhance people's awareness of environmental protection. At the same time, the tourism sector and the tax department to implement the environmental tax, to make people aware of "protect the environment is everyone's responsibility".

Although China adopted the People's Republic of China environmental protection law in April 24, 2014, and began to implement in January 1, 2015. But in the implementation process, especially in remote areas there is still lax enforcement situation. Although the "environmental protection law" to increase the intensity of economic penalties for polluting enterprises, well done enterprises have also developed corresponding incentives, but there are still many loopholes in the actual implementation process. China began to introduce and implement environmental tax, the relevant state departments should pay more attention to the construction of relevant legal system, improve its division of labor, accounting, tax rates and other aspects of the procedural system. Economic measures have become effective and common management measures of environmental protection law. With the strengthening of economic penalties, it is bound to increase the difficulty in the implementation of the protection law. Only by establishing a sound legal system can we better achieve the effectiveness and purpose of economic penalties.

The implementation of the national environmental protection law is from the global overall management of tourism ecological environment in our country, the tourist area of a small part of the management still needs to rely on the local relevant departments. In standardizing the development of local tourism, local management should abandon the "tourism economy first" attitude, increase the investigation and monitoring of green resources within the scenic area. In the understanding of water, soil, air, animals, vegetation and other aspects of the specific circumstances, to develop effective tourism economic development policy. Scenic areas no longer build hotels, cableway, roads, etc., to minimize the destruction of the ecological environment within the scenic spots. Controlling scenic spots entering vehicles, especially during peak season.

\section{Conclusion}

Tourism environment has its own bearing capacity, when tourism reception exceeds its carrying capacity, will inevitably lead to the imbalance of tourism economy and tourism ecological environment. In the process of the development of tourism, local governments and countries should not only attach importance to the development of tourism economy, but also pay attention to the impact on tourism ecological environment. As the root of the whole tourism development, once the tourism ecological environment is damaged, it will affect the development of tourism economy. Government departments and scenic managers should avoid the formation of such a vicious cycle. 


\section{References}

[1] Pang Wen, Ma Yaofeng, Tang Zhongxia. Coupling relationship between tourism economy and ecological environment and coordinated development: a case study of Xi'an city [J]. Journal of Northwestern University (NATURAL SCIENCE EDITION),06:1097-1101+1106, 2011.

[2] Min Shuhui, Zhang Chen. Jiangsu province tourism economy and ecological environment coordinated development evaluation [J]. Journal of Nanjing Institute of Industry Technology,01:5458, 2016.

[3] Wang Lingen, Zhong Linsheng, Cheng Shengkui. Effect of resource and environment research framework and the mechanism of [J]. resources science tourism consumption,08:1452-1464, 2016.

[4] Wang Lifang, Su Jianjun, Huang Yu Xie. Shanxi province Forest Park tourism economic development and ecological environment coordination degree of agricultural technology economic analysis of [J].08:98-104, 2013.

[5] Xiong Xiaohong. Double effect of rural tourism ecological environment and its correct response[J]. technical economics and management research,11:92-95, 2012.

[6] Zhong Xia, Liu Yihua. Analysis of coordinated development of tourism economy ecology environment in Guangdong province [J]. tropical geography,05:568-574, 2012.

[7] Zhao Xin. Coupling relationship between tourism economy and ecological environment and coordinated development [J]. financial problems research, S1:238-240, 2014. 